\title{
Nogle upåagtede kilder til P.F. Suhms bibliotek
}

af fhv. seniorforsker, cand.mag. Harald Ilsøe

Suhms store bibliotek blev som måske bekendt erhvervet 1796 af Det kongelige Bibliotek, hvor benyttere af den ældre bestand ikke sjældent støder på hans ejermærke i bøger og håndskrifter. Det dækkede alle fagområder og indtager en særlig plads i dansk bibliotekshistorie, ikke så meget ved sin størrelse som ved at Suhm generøst stillede det til rådighed for offentligheden en snes år før Det kongelige Bibliotek blev åbnet for publikum. Udlånstiden var normalt en måned, og der stilledes ikke andre betingelser til lånerne end kvittering for de udleverede bøger. At der hermed blev opfyldt et behov fremgår af, at antallet af bøger, der konstant var i udlån til læserne "af alle Borgerklasser, Kiøn og Aldre", plejede at beløbe sig til ca. 1.500. Dette er, hvad en af Suhms samtidige har meddelt, og det er ganske karakteristisk for det kendskab, man i dag har til Suhms bibliotek, at denne og andre væsentlige oplysninger stort set beror på samtidige udtalelser. De udlånsprotokoller, der blev ført, er gået tabt ligesom de af Suhm opbevarede regninger, der ved forhandlingerne om salget til Det kongelige Bibliotek dokumenterede, at han havde anvendt over 120.000 rigsdaler på bogkøb. Da der heller ikke findes en katalog over biblioteket, foreligger der intetsomhelst, der giver overblik over dets omfang eller størrelsen af dets indhold. Det eneste aktmæssige holdepunkt er en tilfældigt bevaret accessionskatalog med købspriser for årene 1785-89. ${ }^{1}$

Siden Chr. Bruun i 1898 publicerede sin grundige biografi af Suhm, er der stort set ikke fremkommet nye bidrag til Suhm-bibliotekets historie. Da 200 -året nu er i sigte for dets indlemmelse i Det kongelige Bibliotek, benyttes lejligheden til at fremdrage nogle hidtil upåagtede kilder for at gå det lidt nærmere på klingen, hvad angår dets størrelse og modtagelse i Det kongelige Bibliotek. 


\section{1: Bibliotekets størrelse}

Samtidige udtalelser om størrelsen varierer fra ca. 90.000 til 200.000 bind. Som det mest plausible skøn har senere bibliotekshistorikere valgt at sætte det til ca. 100.000 bind og kan her henholde sig til et bud givet af Rasmus Nyerup, der som Suhms tidligere bibliotekar og flittige benytter af biblioteket må anses for en god kilde. Bag den slags runde tal kan der jo imidlertid udmærket ligge realiteter på plus/minus 10-15\%, og i størrelsesordenen 90.000 eller derover vil formentlig selv garvede biblioteksfolk have svært ved at afgøre endsige huske, om der har stået lad os sige rundt regnet 80.000 eller 100.000 bind på hylderne. Med al respekt for Nyerup og hans tilhængere forekommer hans angivelse ikke overbevisende, og den holder i hvert fald ikke stand ved en konfrontation med nogle samtidige meddelere, som fra tid til anden har udtalt sig om biblioteket og her skal føres i marken.

Først en svensk lærd, Johan Henrik Lidén, der besøgte København i juni 1768. I en indholdsrig dagbog fortæller han om et besøg hos Suhm, der foreviste ham biblioteket: "Han hade ett ganska stort Bibliothek af sköna Grekiska och Latinska Auctorer, uti historien och myntkunskapen samt naturalhistorien, helt visst till ett antal af 12.000 band. Det indtog hela öfversta vågningen i hans Hus och en del af mellersta. Han ökar stärkt denna Boksamling och hade i dag fått en myckenhet nya böcker fra Holland".2

Fjorten år senere, i juli 1782, dukkede endnu en svensker op og fik med en introduktionsskrivelse $\mathrm{i}$ hånden Suhm til at gentage sin rundvisning. Den besøgende var den unge adelsmand Knud Posse, som i sin dagbog beretter: "Han lod mig straks komme ind i sit berømte bibliotek på 50.000 bind. Det er uhyre stort, men heller ikke opstillet, som man ville forvente; hvad der bidrager hertil er, at det er offentligt, og at enhver her kan låne efter sit forgodtbefindende. Skønt ejeren især beskæftiger sig med historie, er der bøger i alle videnskaber som bibler i alskens udgaver, kirkefædre, teologi, retsvidenskab, matematik osv. Der er en særdeles smuk samling vedrørende historie i Tyskland og Italien, som man sædvanligvis ikke træffer på, men da intet i denne verden er fuldkomment, nævnte jeg nogle nye bøger for ham, som han ikke havde ...

Biblioteket rummer adskillige sjældne bøger, som jeg ikke har set andetsteds og som er så dyre, at man må have Mr. Suhms formue for at turde give sig i kast med dem ..."3

Mellem 1768 og 1782 var biblioteket altså vokset fra 12.000 bind (Lidén) til 
(omkring) 50.000 bind (Posse), tal der uden tvivl er blevet meddelt af Suhm selv. To år senere fik en fransk rejsende ikke overraskende at vide, at biblioteket var steget til "over" 50.000 bind, ${ }^{4}$ og videre frem kan væksten følges via et dagbogsnotat af sydamerikaneren Francesco de Miranda, atter med hjemmel i Suhms egne ord. Miranda aflagde visit i jan. 1788 og skriver om Suhm: "Vi traf ham i hans bibliotek, hvor han som regel er hver formiddag indtil kl. 2, og her tager han imod alle, som ønsker at konsultere ham; han reserverer nemlig natten til sit vigtigste arbejde. Han viste os sit bibliotek, der rummer over 60.000 bind, og som står til rådighed for folk, han kender. Man behøver blot at sende bud efter den bog, man har lyst til at låne, så sender han den omgående. Et eksempel der er højst enestående i Europa. Han fortalte mig, at han mister mange bøger, men han har regnet ud, at tabet ikke overstiger 200 rigsdaler om året, og at han derfor ikke ønsker at berøve publikum denne fordel. Han påtager sig arbejdet med omgående at erstatte de forsvundne bøger ... Jeg bad om at låne Stosch's Cabinet af Winckelmann, som jeg strax fik tilsendt." 5

$\mathrm{Nu}$ bliver det muligt at vurdere den årlige tilvækst. I løbet af de fjorten år fra 1768 til 1782 var biblioteket vokset med ca. 38.000 bind eller 2.714 bind om året, så biblioteket nåede op på 50.000 bind. Lægges en årstilvækst i denne størrelse til grund for tilvæksten i de fem et halvt år, der gik fra Knud Posses besøg i juli 1782 til Mirandas i jan. 1788, skal 2.714 ganges med $51 / 2$ hvilket giver i alt 14.927 bind. Disse lægges så til Posses oplysning om en bestand på 50.000 bind, hvorved bestanden kommer op på 64.927 bind. Selvsagt ikke et præcist, men omtrentligt tal, men dog et tal der stemmer nydeligt med en bestand på "over 60.000", som Suhm anslog bestanden til i Mirandas refererat.

Otte år senere, i marts 1796, blev biblioteket så afhændet til Det kongelige Bibliotek. Beregnes den årlige tilvækst fortsat med et gennemsnit på 2.714 bind, udgjorde tilvæksten 1788-96 2.714 gange $8=21.712$ bind. Slutfacit: Suhms bibliotek bestod i 1796 af 64.927 plus $21.712=86.639$ bind. En skønsom justering af tallet må afgjort gå i nedadgående retning, da Suhm i 1790erne vides at have fået en i forhold til tidligere vaklende økonomi, hvad der iøvrigt - foruden indgåelsen af et nyt ægteskab - menes at have været medvirkende til, at han gik i forhandling om salget. Denne ikke uvæsentlige omstændighed medfører, at væksten i de senere år nok bør reduceres med et par tusinde bind, hvoraf følger, at biblioteket på sin højde maksimalt kan have udgjort ca. 85.000 bind, måske lidt færre. Beregningen er 


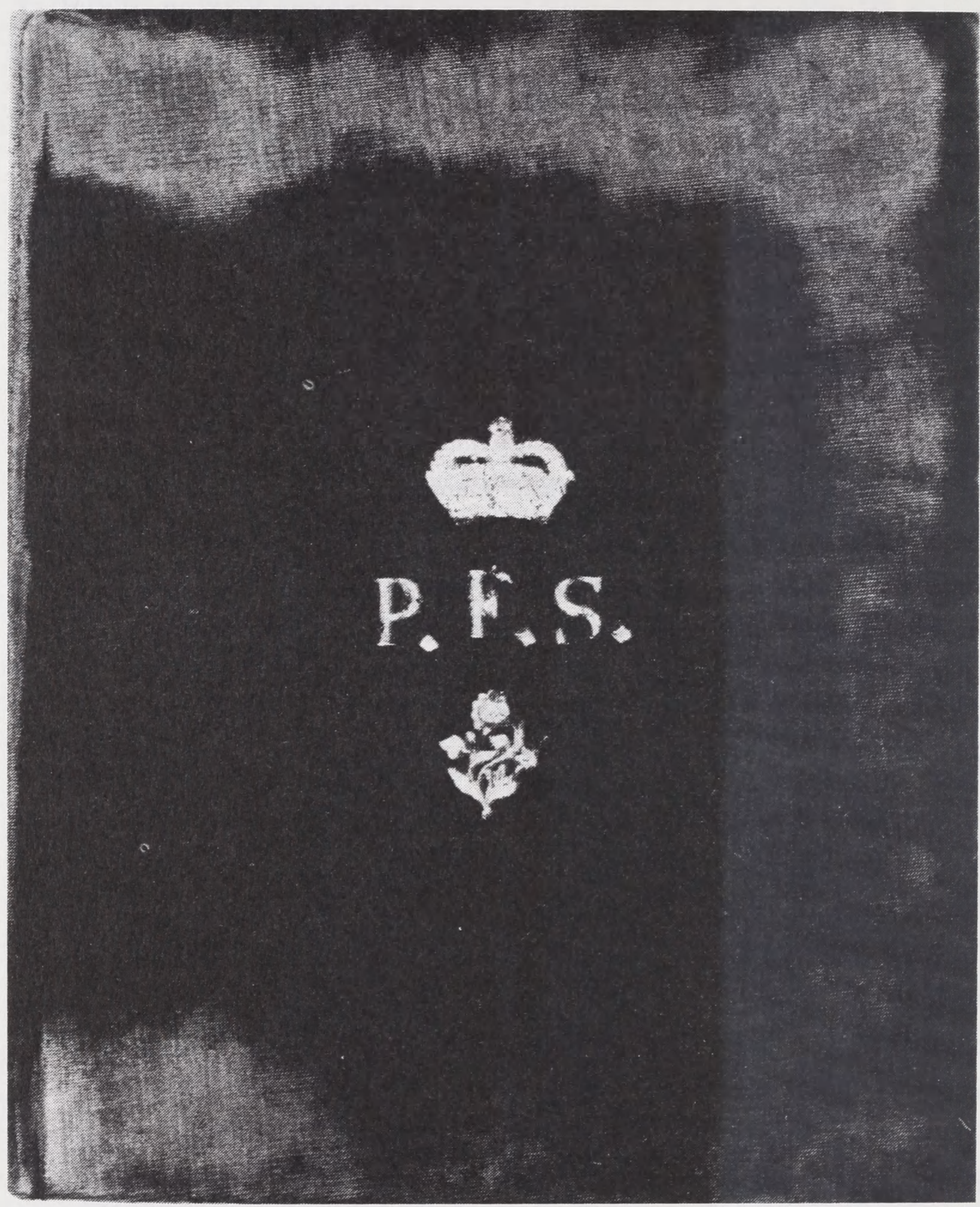

Som rundhåndet mæcen modtog Suhm adskillige dedikationseksemplarer. Litteraten J.L. Bynch overrakte ham 1772 en lille tryksag i form af "Et Brev til Hr. Konferentsraad Peter Frid. Suhm", ubetydelig af indhold, men indbundet i rødt fløjl med Suhms navneinitialer og ornamenter i forgyldning.

uden sikkerhedsgarantier, men dog at foretrække frem for det gængse og ikke nærmere motiverede skøn på ca. 100.000 bind eller andre størrelser. Skulle tallet 100.000 fastholdes, forudsætter det for de sidste otte år en lidet sandsynlig forøgelse af accessionen til ca. 4.380 bind om året. At det mere beskedne tal også lader sig bedre forene med oplysninger om, hvad Det kongelige Bibliotek lod henholdsvis ind- 
lemme og udskille som dubletter, vil fremgå af næste afsnit.

Som endnu en kilde foreligger det allerede omtalte fragment af en accessionsprotokol for årene 1785-89 (nu NkS 2274 4to). Men den omfatter hverken bøger modtaget som gave eller håndskrifter og synes også på andre måder at være ufuldstændig, og selv om der tages højde for nogle gennemskuelige lakuner, når en beregning af gennemsnittet af den årlige tilvækst for årene 1787-89 ikke højere op end på en ca. 1.600 bind. Kan protokollen overhovedet bruges som et mål for accessionen, peger den altså snarest på et slutfacit mindre end det ovennævnte og bestyrker forsåvidt antagelsen, at tallet 85.000 må være et maksimumtal.

\section{2: Dubletterne}

Ved modtagelsen i Det kongelige Bibliotek blev håndskrifterne stillet til side og måtte vente, til en katalogisering omsider blev foretaget $\mathrm{i}$ årene 1831-32. De indgik da som grundstammen i en "Ny kgl. Samling" (NkS), men desværre uden markering af, hvad der stammede fra Suhm, og hvad der var indgået andetstedsfra. Bøgerne derimod blev snart efter modtagelsen sammenholdt med bibliotekets forhåndenværende bestand og dem, der fandtes i forvejen, udskudt som dubletter. Nettoresultatet af nytilkomne bøger blev ikke opgjort, men ansås efter én kilde at have udgjort ca. halvdelen af de dengang anslåede 100.000 bind, dvs. ca. 50.000 bind, efter en anden, lidt mere velovervejet kilde noget færre, hvad der formentlig vil sige omkring 40-45.000 bind. Hovedparten af dubletterne blev i 1811 skænket af kongen til det nyoprettede universitetsbibliotek i Christiania (nu Oslo), og når man fra norsk side har angivet boggavens størrelse til 29.000 bind, ${ }^{6}$ vil det ses, at dette antal falder betydeligt bedre i hak med en beregning af Suhms bibliotek til ca. 85.000 end til ca. 100.000 bind, omend der stadig forbliver en manko mellem de 85.000 bind og en sammenlægning af bøgerne fordelt på biblioteksinstitutionerne i København og Oslo, efter de foreliggende oplysninger at dømme højest ca. 45.000 plus ca. 29.000 = ca. 74.000 bind. Dvs. en manko på ca. 11.000 bind. Af de manglende bind udgjorde håndskrifterne ganske vist op $\bmod 3.000$, så for at få regnestykket til at gå op kræves der kun en forklaring af, hvad der kan være blevet af ca. 8.000 bind. Med alle disse mere eller mindre løse tal ville det sandt nok være lidt mistænkeligt, om der ikke blev noget til rest, og differencen skal da heller ikke søges bortforklaret. Men ved inddragelse af en engelsk kilde kan den gøres noget mindre.

Fra Werlauffs bibliotekshistorie har det længe været kendt, at der til biblioteket 
"tiltuskedes i 1799 fra en Boghandling i Edinburgh en betydelig Deel af den nyere engelske Litteratur for Doubletter". Holsteneren August Hennings har i sin dagbog fra et ophold i København 1802 skrevet ganske meget om Det kongelige Bibliotek, til dels med overbibliotekar D.G. Moldenhawer som kilde, og var både underrettet om, at disse dubletter hidrørte fra Suhms samling, og at de indbragte bøger fra den engelske boghandler for et beløb af 5.000 rigsdaler: "Der König hat aus der Suhm'schen Bibliothek 90.000 Bände [Bücher] und 6.000 Bände Handschriften erhalten, welches zu einer Menge Doubletten Anlass gegeben. Davon hat ein Engeländer durch einen Tausch gegen englische Werke für $5.000 \mathrm{r}$. an sich gebracht. Damit war eine grosse Lücke in der englischen Litteratur gehoben".7 Hvordan denne engelske transaktion blev bragt i stand, kan nærmere udforskes i bibliotekets arkiv, men spørgsmålet hvordan er i nærværende sammenhæng mindre interessant i forhold til den gode kendsgerning, at der er bevaret en salgskatalog over de pågældende dubletter. Katalogen er fra boghandler William Laing i Edinburgh, og ikke uden sans for den reklameværdi, der lå i bøgernes proveniens, sørgede han for, at denne samling antikvariske bøger fra kongens bibliotek i København blev annonceret i titlen: A Catalogue of Books to which is added a Supplement, containing the Duplicates of the King of Denmark's Library at Copenhagen. Now on Sale (for ready money) at W. Laing's Bookseller, Head of Canongate, Edinburgh 1800.

Katalogen er indlemmet i bibliotekets Danske Afdeling i finansåret 1939/40, men synes trods behørig registrering i den systematiske katalog under Det kongelige Biblioteks historie at have henlevet sine halvthundrede år i biblioteket i al ubemærksomhed. ${ }^{8}$ Supplementet med dubletterne optager 26 sider (s. 139-64) og indledes efter et deltitelblad med en præsentation, hvor der atter fremkommer en variantangivelse af Suhm-bibliotekets størrelse, denne gang meget mådeholdent: "over 60.000 bind". Ingen mors sjæl har tilsyneladende haft noget præcist begreb om den endelige størrelse, og Laings sandsynlige kilde har endda været hans danske kontaktmand B.G. Niebuhr. Den senere så berømte historiker havde nylig været ansat ved Det kongelige Bibliotek og foretog derefter en udenlandsrejse, som 179899 førte ham til Edinburgh, hvor han på bibliotekets vegne forhandlede med Laing om dublet-afhændelsen. ${ }^{9}$

Præsentationen lyder:

"The Royal Library at Copenhagen is generally allowed to be the best Collection 
in the North of Europe. It was considerably enriched by the valuable Library of the late learned and celebrated Mr. Suhm, which exceeded 60.000 volumes, and which he bequeathed to the King. In consequence of this great acquisition, the Duplicates became so numerous, as to amount to many thousand volumes, from which the following Supplement has been Selected, as most congenial to the literaty taste of this country. It is hoped that those who wish for rare and valuable works, will avail themselves of the present opportunity, as such a collection may never be offered again to the Public.

The Books are general in fine condition, and notwithstanding the late Duty on Importation, which almost amount to prohibition, and other encreased Expences, they will be Sold at the former Prices, and many of them lower."

Derpå følger selve katalogen med 158 titler i folio, 271 i kvart og 272 i oktav og mindre formater, ialt 701 katalognumre. Mange af bøgerne er i to eller flere bind, og enkelte numre dækker over store samlinger af udgaver som f.eks. nr. 6031: "Collection of Books published by T. Hearne, the Antiquary - in all 46 vol., very fair and scarce", eller et periodicum som nr. 5767: "Philosophical Transactions of the Royal Society of London from their Commencement, in 1665 to 1795 inclusive, 80 vol." Antallet af bind er derfor væsentlig højere end antallet af titler, vel op mod 1.500. Heraf følger, at den lidt generende manko i regnestykket på ca. 8.000 bind i det mindste kan nedbringes til ca. 6.500. Denne rest kan man så resigneret lade stå i erkendelsen af, at der ved slige beregninger må være en vis usikkerhedsmargin. Bl.a. kan Laing have solgt bøger fra sin danske akvisition uden om katalogen, ligesom Det kongelige Bibliotek vides at have afhændet yderligere et antal dubletter til anden side. ${ }^{10}$ Men da det tidligere fremkomne facit på ca. 85.000 bind var at anse for et maksimumstal, og når andre forhold peger i nedadgående retning, må en konklusion gå ud på, at Suhms bibliotek antagelig har bestået af et sted mellem $c a$. 80.000 og 85.000 bind. Et nøgternt, begrundet bud på størrelsen af dette imponerende bibliotek, som på ingen måde forringer dets ry i andre henseender. Et sikkert tal vil man nok aldrig nå frem til.

\section{3: Lidt mere om Laing's katalog}

Med William Laing's katalog er fremdraget både et lille bidrag til Det kongelige Biblioteks historie og et stykke Suhmiana, hvori der gives en smagsprøve på de mange herligheder, Suhms gæster beundrede, når de aflagde visit. Som et af de 
1727 Anderfoni Diplomatum et Numifnatum Scotix, cum prefa. tione Ruddimani, Large Paper, fine copy, gil, 71 is Ed. 1735

5718 Boethii Hiftoria Scotorum, beft edit. fine copy in Vellum, $16 \mathrm{~s}$

- Paris 1578

5719 Rerum Anglicanum Scriptores Veteres, a Gale et Fell, 3 vol. befe edit. fair, 31 - Oxon. 1684

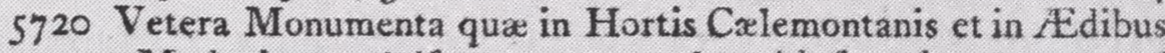
Mathriorum Adfervantur, 3 vol. with fine plates, new and elegantly bound, $818 \mathrm{~s} \quad-\quad$ Rome 1779

5721 Mufeum Mazzuchellianum, 2 vol. eleg. $414^{\mathrm{s}}$ Venet. $176 \mathrm{r}$

5722 Pafferii Lucerna Fictiles Mufei, 3 vol. plates, very neat and gihe, $3^{1} 3^{s}-$ - Pif 1739

5723 Hippocratis Opera, Gr. et Lat. Foefi, 2 vol. befl edit. balf bound, uncut, 189 Gen. 1657

$572+$ Clavii Opera Mathematica, 2 vol. neat, $18 \mathrm{~s}$ Argeat. 1612

5725 Meflenii Scandia Illuftrata, 2 vol. gill, 1111 s $6 \mathrm{~d}$

5726 Sadi Rofarium Politicum, five Theatrum Amonum Sortis Humanx, Perf. et Lat. a Gentio, fine Copy, very rare, $3^{l} 3^{s}$ - - Amft. 165 I

5727 Lupi in Vet. Gr. Infcript. Severee et aliifq. Monumentis Roma, Nuper Refolis, plates, gill, 9s - Par. 1734

5728 Cardani de Rerum Varietate, firfl and bef edit, il is Baf. 1557

5729 Metopofcopia, curiaus beads, fine copy, 18s Par. 1558

5730 Bartholomeus Anglicus de Proprietate Rerum, neat, $756 \mathrm{~d}$ - Nun. 1492

5731 Golii Lexicon Ambicum, fine Copy gith, 31 1 $356 \mathrm{~d}$ L. Bat. 1653

$573^{2}$ Du Frefne Gloffarium ad Scriptores Medix et Infima Latinitatis, 6 vol. befl edit. gill, sl los - Paris 1733

5733 Scherzii Gloflarium Germanicum, ed. Oberlin, 2 vol. newv and gilt, 31 108 - Argent. 1 jor

5734 Scapula Lexicon, Gr. et Lat. bef edit. fine Copy in vellum, 21 r2s 6d L. Bat. 1652

5735 Conftantini Lexicon, Gr. et Lat. 2 vol. now and eleg. in vellumi, $4^{1} 4^{s}$

Gen. $152^{2}$

5736 Pelletier, DiCtionnaire de la Langue Bretonne, gilt, $2 \mathrm{l} 2 \mathrm{~s}$

5737 Bullet, Dia. de in Langue Celtique, 2 vol. gilt, Il $1175 \mathrm{~d}$

$573^{8}$ Georgi Alphabetum Tibetarium, neas, $188 \quad \begin{array}{r}\text { Bef. } 1754 \\ \text { Rome } 1762\end{array}$

5739 Houbraken and Vertue's Heads of Illufrious Perfons of Great Britain, with their Lives by Bireh, Laraz Papzr, very firl impreffions, balf bound, uncut, rol 105

1749

$574^{\circ}$ Ridinger's plates of Animals, fine copy, $4^{1} 4^{s}$

5741 Holingthed's Chronicles of England, Scotlend and Ireland, 2 vol. forf edit, witb wooden cuts, very foir, 41 s Lond. 1577

5742 Grafton's chronicle at Large, and meere Fittory of the Affairs of England, in the Original bindiag, 31 3s ib. 1569

Bøger fra Suhms bibliotek i Laing's katalog. 
sjældneste og dyreste værker står forrest i katalogen den store og berømte polyglotbibel (bibel trykt på mange sprog), der udkom i seks bind i Spanien 1514-17 (nr. 5606, pris 52 pd. 10. sh.). "Very fair copy, in the original binding", tilføjer katalogen og oplyser, at "This book is extremely rare, and seldom occurs for sale in Britain". Noget desorienterende er det dog at se værket beskrevet her, for Suhms eksemplar befinder sig faktisk i Det kongelige Bibliotek den dag i dag. Forklaringen er naturligvis, at man i visse tilfælde har valgt at udskille et ældre, måske mindre velholdt eller ukomplet eksemplar som dublet, fordi Suhms eksemplar har været i bedre stand. I så henseende er katalogen følgelig ikke helt pålidelig, ligesom der er smuttet et par bøger med, som med trykår 1798 umuligt kan være indgået som dublet i 1796. Men i det store og hele må det vel antages, at Suhm har ejet de pågældende eksemplarer.

Et andet spørgsmål melder sig over for katalogens påfaldende store mængde af litteratur inden for fysik og naturhistorie, et område som ikke var Det kongelige Biblioteks stærke side. Skulle nogle af disse bøger mon være blevet udskudt, fordi de blev anset for biblioteket uvedkommende, snarere end fordi de var dubletter? En eventuelt undersøgelse heraf må overlades til Danmarks Natur- og Lægevidenskabelige Bibliotek, hvor den gamle naturvidenskabelige bestand nu befinder sig. Derudover forekommer der ganske mange klassikerudgaver og talrige historiske værker og kildesamlinger, det sidste ikke så mærkeligt, da Det kongelige Bibliotek især på dette felt var velforsynet og historie udgjorde Suhms livslange interesse.

Af tryk før 1500 (inkunabler) er der en 6-7 stykker, deriblandt førsteudgaven af Homer fra 1488 (nr. 5680, pris 14 pd.) og af Aristoteles-udgaven i fem bind fra 1495-98 (nr. 5683, pris 8 pd. 8 sh.). Lagt til de godt 75 inkunabler i Det kongelige Bibliotek og universitetsbiblioteket i Oslo, der ses at have tilhørt Suhm, har hans samling af inkunabler således rundet de 80 , uden at han dermed skal betegnes som just inkunabel-samler. Bogsamler af bibliofilernes æt var Suhm ikke, men han har dog åbenbart også ejet den smukke og eftertragtede folioudgave af Teuerdanck illustreret med træsnit fra 1517 (nr. 5677: "a very fine and perfect copy, bound in vellum", pris $10 \mathrm{pd} .10$ sh.). Og vil man vide, hvad nogle kendte danske pragtværker blev vurderet til, kostede f.eks. de seks første bind af Flora Danica, 1766-98, 18 pd. (nr. 5615), mens der for Regenfuss' konkylieværk fra 1758, med de fornemt kolorerede tavler måtte betales 12 pd. 12 sh. (nr. 5617). Som kyndig antikvarboghandler var Laing i stand til at oplyse om konkylieværket, at "This is one of the few 
copies which were painted for the King as presents. They are distinguished by the Frontispieces being printed in red, which in the common copies are blue". Saffremt oplysningen er rigtig, synes den siden at være blevet glemt. ${ }^{11}$

En egentlig gennemgang af katalogen skal ikke foretages. Blot til orientering og afrunding: Boghandlerfirmaet Laing opretholdt længe forbindelse med Danmark. På auktionen over Moldenhawers bibliotek i København 1824 gjorde William Laing store køb, i 1840 formidlede sønnen David en skotsk boggave til Det kongelige Bibliotek og sendte det personligt gaver så langt frem som til 1861.12 Et engelsksproget håndskrift med en beskrivelse af København (NkS 670 4to) havde han ved tidligere lejlighed skænket biblioteket. Det bærer påtegningen: "David Laing. Bought at Mr. Bain'es Sale. Presented to the Royal Library of Copenhagen. Octr. 16., 1819."

Noter

Oplysninger om Suhms bibliotek er samlet i E.C. Werlauff: Historiske Efterretninger om det store kongelige Bibliohek $i$ Kiøbenhavn, Kbh. 1844 (se reg.) og Chr. Bruun: Peter Frederik Suhm, Kbh. 1898, s. 206-14 og 378-99. Når ikke anden henvisning gives, er disse forfattere, som al senere litteratur bygger på, benyttet som kilde.

2 Johan Henrik Lidéns rejsedagbog i Danske Samlinger II, 1866-67, s. 333f.

3 Knud Posses rejsedagbog i Uno Willers: En gustaviansk boksamlare. Knut K:son Posse på Svanå ( = Äten Posse III), Sthlm. 1971, s. 69; citatet oversat fra fransk.

4 Anonym "Voyage de Dannemarck" fra 1784 i Collection de voyages faits autour de monde, Paris (ca. 1788), s. 34.

5 Miranda i Damark. Francisco de Mirandas danske rejsedagbog 1787-1788, ved Haavard Rostrup, Kbh. 1985, s. $102 \mathrm{f}$.

6 Kilden er Jens Kraft: Topographisk-statistisk beskrivelse over Kongeriget Norge, I, Chria 1820, s. 179: dubletoverførslen bestod af 4.000 bind i folio, $5.000 \mathrm{i}$ kvart og 20.000 i oktav (jvf. Werlauff s. 256 note o). Også i senere norsk bibliotekslitteratur henholder man sig til de ca. 29.000 bind, W. Munthe angiver præcist 29.040 bind i Haandbog i Bibliotekskundskab, udg. af Svend Dahl, 3. udg., II, 1927, s. 166.

7 Werlauff s. 258; August Hennings' Dagbog under hans Ophold $i$ Kobenhavn 1802, Ved Louis Bobé, Kbh. 1934, s. 150.

8 Hertil kan have bidraget, at katalogen ikke er medtaget $\mathrm{i}$ det trykte supplement til Bibliotheca Danica, Kbh. 1963.

9 Ada Adler: D.G. Moldenhawer og hans Haandskriftsamling, Kbh. 1917, s. 161.

${ }^{10}$ I 1811 blev der også afgivet dubletter til gymnasiet i Altona og Jonstrup Seminarium og $\mathrm{i}$ årene omkring 1820 til stiftsbibliotekerne i Ålborg og Roskilde, alle dog i mindre omfang.

${ }^{11}$ Jvf. Danske Boghaandvark gennem tiderne 1482-1948, red. af Palle Birkelund, Kbh. 1949, nr. 119 s. 79.

12 K.F. Plesner: Danske bogsamlere i det nittende århundrede, Kbh. 1957, s. 28; Werlauff s. 355; om gaver 1858-61 oplysninger i bibliotekets arkiv, F 62 . 